\title{
BLITZKREIG INVERTED OR THE RETIARIUS'S NET
}

\author{
An Option for the Conventional Defence \\ of the Republic of South Africa
}

\section{H. R. HEITMAN}

The conventional option is possibly more attractive to the Republic of South Africa's enemies and, therefore, more deserving of consideration, than generally thought. Both long term trends and more recent events will have served to make it more so These include:

1. The gradual upgrading of potentially hostile military establishments, particularly as regards personnel background and equipment.

2. The improving infrastructure of Southern Africa generally, facilitating the conduct of conventional operations

3. The establishment of openly Marxist regimes in Angola and Mocambique, facilitating access.

4. The experience gained as a result of the operations in support of the Movimento Popular de Libertacao de Angola (or Popular Movement for the Liberation of Angola).

5. The increasingly supine and even hostile attitude of the West, the United States of America in particular

6. The increasingly active role of the Soviet Union and her allies.

7. The high losses among, and the relative lack of success of, terrorists operating against Rhodesia, resulting in a decrease in confidence in this approach.

9. The South African role in Angola which, suitably embellished, can be presented as evidence both of the Republic of South Africa's 'wickedness' and her military weakness.

The Angolan episode has admirably demonstrated the Soviet Union's ability to deploy large, mechanised, formations and/or specialists over great distances with relative ease. Here it must also be stressed that a force intended to deal with the South African Defence Force will be rather more formidable in all respects than that encountered in Angola. Too much store should, therefore, not be placed in the performance of the opposition during that episode. On the other hand, a conventional assault upon the Republic of South Africa would be most impractical were Rhodesia, as it is now, not first removed from the scene.

Any conventional operations against the Republic of South Africa would in all probability be based upon Soviet doctrine adapted to local conditions. The force: space relationship, in particular, would dictate a columnar form of warfare. Further, it would be necessary to allow for the idiosyncracies of the local forces employed. Even so, there are still many options within the conventional spectrum. The following is offered as an outline characterisation of the most probable:

1. The assault would be overland.

2. Its primary objective would be the destruction of the South African manoeuvre ${ }^{2}$ forces.

3. It would be carried out by mechanised forces.

4. These would comprise formations based on the Soviet pattern motorised rifle division, probably with additional armour and artillery.

5. Soviet doctrine could well be sufficiently adapted to allow these to deploy self-contained regimental combat teams operating independently.

6. The attacking forces would advance speedily along available roads and, where necessary, cross-country; contacting, concentrating upon and engaging the South African manoeuvre forces, bypassing other serious opposition.

7. Tactical air/heliborne operations designed to facilitate the advance are likely to be integral to the overall scheme.

8. Some tactical air support would be provided.

9. Counter-air strikes are a distinct possibility.

10. The attacking forces would be issued with antiaircraft equipment on a lavish scale.

11. The effectiveness and, more particularly, the efficiency of the attacking forces would be adversely affected by:

a. The relatively poor quality of available indigenous personnel and

b. The difficulties of co-operation between these and the 'imported', particularly command and specialist, elements.

This would militate against night operations in particular. In view of Soviet partiality to these,

1. That is between the guerilla and nuclear levels.

2. That is those forces primarily intended for the conventional role. 
however, they must still be regarded as highly probable.

An assault as outlined above could prove extremely embarrassing to the South African Defence Force - particularly if unexpected and supposedly impractical axes of advance are, as is quite likely, chosen. The situation is further aggravated by the pertaining force: space ratio and the extreme length of the borders in particular.

Considering possible countermeasures, it is immediately apparant that a mobile form of defence is essential. Here, however, a problem is encountered: a mobile defence on the strategic ${ }^{3}$ level a la Manstein is not really feasible as it requires the trading off of more territory than the Republic of South Africa can afford. In this regard the proximity of the vital Rand complex to the border, in particular, should be borne in mind. Similarly, the pertaining force: space ratio virtually precludes a purely tactically mobile defence as epitomised by Colonel Avigdor's operations on the Golan in October 1973. An intermediate solution is therefore required. The following is an attempt to outline one such possibility.

The approach to be put forward here envisages the division of the ground forces as follows:

1. The Territorial Forces: Their primary function would be the maintenance of internal security. Additionally they would provide infantry support to elements of the manoeuvre forces operating within their areas.

2. The Manoeuvre Forces: These would deal with any conventional threat and would comprise:

a. Covering Forces deployed near the borders and intended to delay the enemy while gathering information and trading off the minimum in casualties and territory. They would operate under the appropriate territorial commander or, in the event of major operations in their area, under the officer appointed to overall commend thereof. By virtue of their function they would be more or less territorially bound. These forces are the chief point of this paper and will be discussed in greater detail below.

b. A Stategic Reserve deployed in the depth of the Republic of South Africa and comprising chiefly of armoured and some airmobile formations. Its primary function would be to conduct the counter-offensive once it is fully mobilised and a propitious moment has been detected. No time lapse between the delaying and counter-offensive phases is envisaged.

Briefly, this is an attempt to avoid the problems of the two above-mentioned approaches while retaining their advantages. In particular, it seeks to minimise the problems resulting from the long mobilisation times of major formations. It must be remembered that even the so militarily conscious Israelis were 'surprised' in 1973, only being saved from a very tricky situation by their forward units. The system suggested here also assumes that the Republic of South Africa must fight a 'short and sharp' war in the event of a conventional situation arising. Thus the emphasis would be on combat elements with only a small manpower reserve. It would thus be possible to field more combat units.

The primary function of the Covering Forces would be to gain the time required for the strategic reserve to be fully mobilized and brought into action en bloc. ${ }^{4}$ In the process it may well be possible to inflict considerable casualties, prevent concentration and to canalize the hostile thrusts into preselected killing grounds. In view of their mission, the probable force ratios and the distance to be covered, a mechanised type of unit, would appear to be indicated as the basis for the Covering Forces. Prime requirements would be operational and tactical mobility and very rapid mobilization and low time into action. The former could be achieved by the use of suitable wheeled vehicles while the latter would be facilitated by keeping the units small and the equipment relatively simple. Keeping the units small would allow them to be manned largely if not entirely from among the population of their base towns or districts. Such units could then also be handled by citizen force officers. Gaps and specialist positions could be filled with National Servicemen and permanent force personnel. Simple equipment would reduce maintenance requirements and the time from storage into action. It should be possible to achieve a mobilization time of a few hours at the most.

In action these units would almost certainly face considerable odds and be forced to rely greatly

3. What the Germans would, more correctly, have called the operational level. See Manstein's campaigns on the Russian front.

4. In accordance with Guderian's 'nicht klecken, klotzen! principle. 
upon their mobility both for security and effect. The immediately apparent parallel is that of the Blitzkrieg doctrine. Essentially, this amounted to the application of Liddel-Hart's twin concepts of 'The Indirect Approach' and 'S trategic Paralysis'. The key to this aplication lay in the so-called 'fast formations'5. These penetrated into and disrupted the enemy's rear areas, Indirect Approach. The resultant confusion, lack of replenishment and breakdown of effective control generally, fixed the enemy for the following infantry formations to deal with Strategic Paralysis. Often the initial thrust(s) and the resultant confusion led to the opposing forces breaking up, thus allowing a defect in detail to be inflicted. For their own security the 'fast formations' relied largely upon their mobility and high density as well as the sort duration of the operation as a whole.

An inversion of this doctrine would appear to be ideally suited to the role of the covering forces. They would thus attempt to 'paralyse' the advancing hostile columns by means of raids and ambushes by fire. These need not be restricted to the services elements. Other lucrative targets would include reconnaissance elements, advance detachments and other more or less independent groups. Headquarters and artillery sites could also prove worthwhile if difficult. Soviet doctrine provides targets of this nature in some profusion and its adaptation to Southern African conditions could only enhance this aspect. Flank guards, however, should generally be avoided as Soviet doctrine appears to concentrate anti-tank guided missiles here. With most actions probably at company or platoon level, the covering forces would, in effect, be conducting mechanised guerrilla warfare slowing and wearing down the enemy, confusing and frustrating his command element and, perhaps, canalizing his thrusts. While it is unlikely that true 'paralysis' could be achieved, sufficient friction could certainly be imposed to achieve the desired end. The role of these Covering Forces would be that of the retiarius' net - to tangle up the opponent sufficiently to allow him to be safely despatched with the trident.

The Covering Forces would do their utmost to avoid serious combat, as this is not their function and can, in the long run, only go against them. An exception to this rule would apply where a concentration upon an isolated enemy force is possible, producing markedly favourable odds. Such an opportunity should be taken as long as the primary function is not thereby compromised. During a counter offensive phase, a greater willingness to accept serious combat would be in order, but the primary role would remain that od harassment. The Territorial Forces could prove of considerable assistance during the delaying phase. 'Stay behind' elements could attempt to hold the more important localities and features, thus further complicating the enemy's situation. The enemy forces covering them would also provide lucrative targets for the Covering Forces. The term 'hold' as used here could include everything from actual physical possession to simply contesting possession, the effect would be the same. Similar support could be provided by airmobile elements although it might be wiser to retain these until after Clausewitz' 'Culminating Point' has been reached. While air support would be highly desirable, the South African Air Force would probably spend much of the delaying phase contesting air superiority. Helicopters, however, should be available and could prove invaluable in both logistic and mobility roles.

With both the basic doctrine and the suggested modus operandi outlined, it now remains to consider the structure of such a covering unit. Considering the responsibility devolving upon such a unit, the brigade level appears indicated. As has already been mentioned, a mechanised unit comprising only wheeled vehicles would offer the best combination of mobility and relative simplicity. A wheeled unit is also extremely efficient in its fuel usage which would enhance its flexibility considerably relative to a tracked one. With modern equipment it is also possible to provide the necessary fire power.

In view of the primary role and also in the interests of reduced size, it should be possible to keep the infantry element to a minimum. What infantry is included would handle the more 'delicate' tasks and also provide security. The inclusion of conventional artillery would be impractical as towed pieces would be too inflexible and manpower-intensive, while self-propelled mounts on wheeled chassis are not yet available. To some extent the provision of self-propelled $120 \mathrm{~mm}$ mortars could compensate for the dropped artillery. Should the personnel and resources be available, the provision of multiple rocket launchers would merit serious consideration. Their effect on a unit caught in the open is unparalleled and they would be well suited to operating with the covering forces. ${ }^{6}$

\footnotetext{
5. The 'schmellen Vertamete' theamouredandmotorised (iIvision!s

6. Consider, also, the possibilities of scatter mine systems.
} 
Considering the above and all the factors discussed in the bulk of the paper, the Bundeswehr's experi-

However, such a brigade would almost invariabiy operate deployed into combat groups based on the armoured car battalions. This could advantageously mental Panzerbrigade 80 suggests itself as a suitable basis for the required units:

be adopted as the normal structure, particularly where a brigade has to be based on several localities. An example of such a structure is shown below:

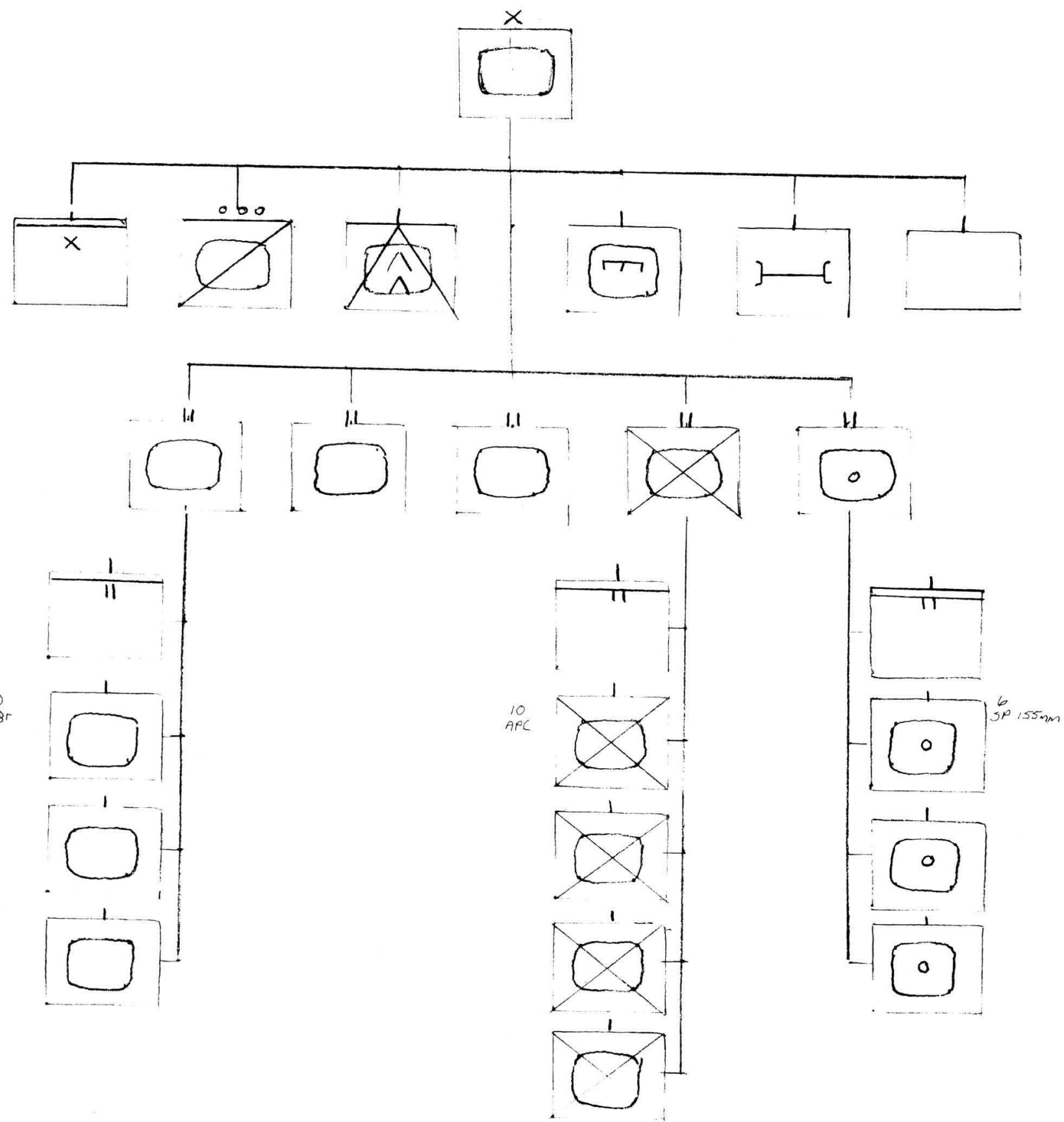

DIAGRAM 1 
Thus restructured, such a brigade would comprise some 2500 men and around 700 vehicles.
It would field 108 heavy armoured cars in combat platoons as well as at least 18 Hot vehicles and 18 self-propelled $120 \mathrm{~mm}$ mortars.

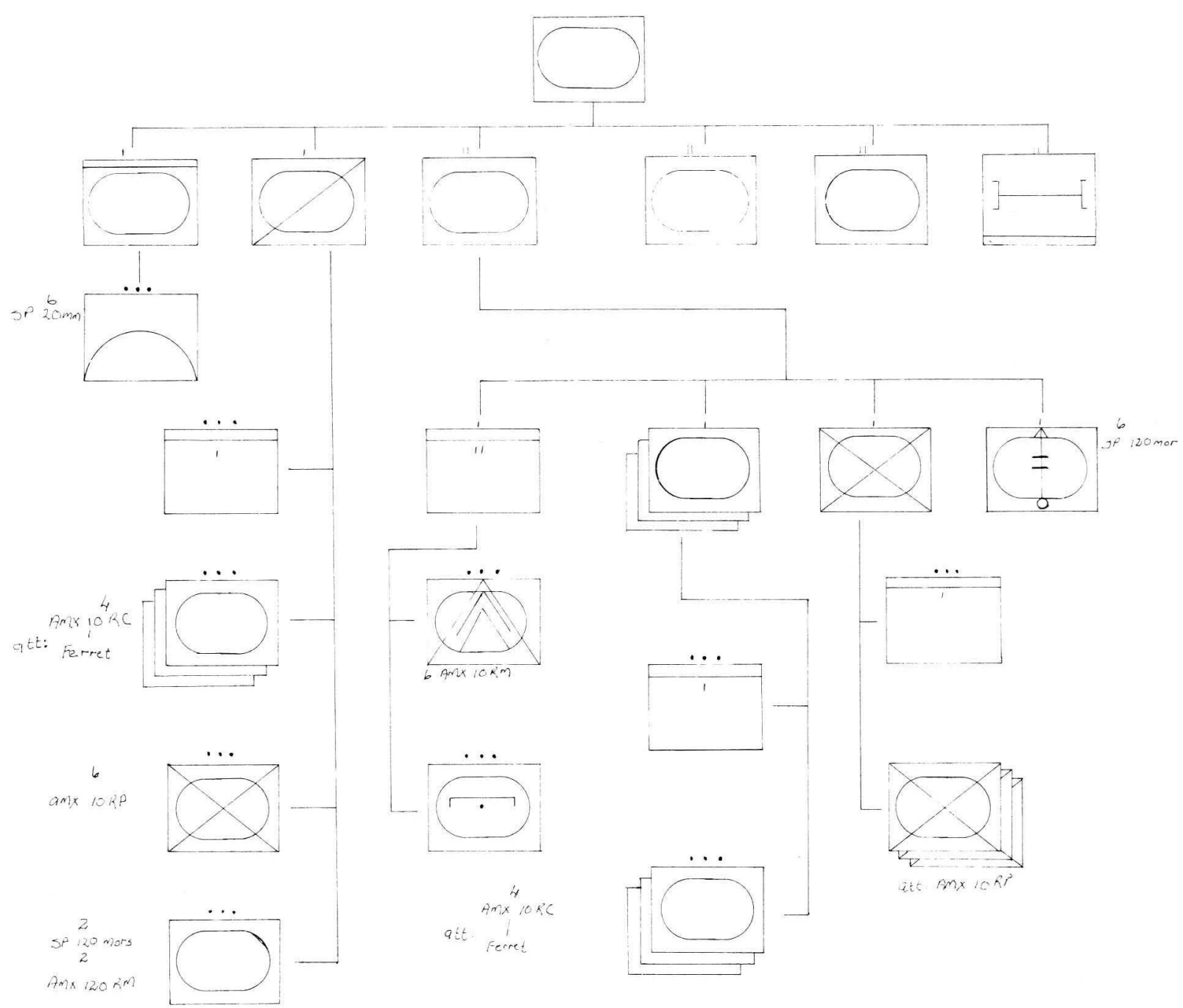

DIAGRAM 2

In either event, the basic combat element would be the armoured car platoon with four heavy armoured cars and one Ferret/Vixen type vehicle. The latter is intended for scouting and liaison duties; it could also be equipped with Hot, Milan or, for that matter Stinger ${ }^{9}$. Overwatch and extended range capacility would be provided by the Hot vehicles. The mortars would provide normal fire support and could also conduct 'artillery ambushes'. The reconnaissance company shown in diagram 2 doubles as a reserve as will be clear from its structure.
7. The Hot (Haut Optiquement teleguide 'tire' d' un Tube) anti-tank 'missile' is a heavy, anti-tank, wire-guided weapon. It has the same general princples of operation as the Milan, but is larger with a higher performance. The Hot is designed primarily to operate from armoured (or un-armoured) vehicles and helicopters.

8. The Milan (Missile $d^{\prime}$ Infantrie Leger Antichar) is an advanced, second generation, wire-guided, spin-stabilisedanti-tank missile system. Guidance is semi-automatic utilising automatic command wire-guidance and optical tracking of the target.

9 The Stinger is a portable anti-aircraft missile previously. known as the Redeye II. It uses a passive infra-red homing device (seeker) which enables the missile to home on the exhaust plume of an aircraft engine. 
Many other organisational forms are, of course, possible - particularly if a size increase is considered acceptable. In such an event, it might be worthwhile seriously considering applying the square structure throughout as regards the armoured elements: that is four combat groups at four armoured car (at four platoons), one mechanised infantry and one mortar companies. Increases in particular weapons would then also be possible. A completely different solution would be to have a mechanised division controlling four to six mechanised regiments and, perhaps, some supporting weapons. Each regiment would be a somewhat enlarged version of the outlined combat-group. In the long run, such a structure would probably be the better but would involve a considerably greater investment of both men and resources, even overall.

For the present, a brigade form much as outlined above would probably be the best structure for the covering units. Not only would such brigades be small enough to be manned and handled by citizen force personnel, it should also be possible to form them with the minimum of 'collateral damage'. The South African army already operates large numbers of wheeled combat vehicles and has built up a vast fund of experience in the process. Relatively little training/ retraining would thus be required, particularly if such brigades were based on existing armoured car units. Initially, also, existing equipment would be quite adequate. Thus it would be possible to form one or more of these brigades on an experimental basis without incurring any great costs. Once they have been proven and a final Table of Organisation and Equipment has been adopted, procurement could begin and further units could be formed. At this stage, of course, more suitable equipment would have to be obtained.

There is a vehicle already available that would be ideally suited to the envisaged role: the AMX-10RC. This $6 \times 6$ vehicle combines excellent mobility at all levels with an impressive armament:

Crew:

Armament:
4 (3 Man Turret)

$1 \times$ MECA $105 \mathrm{~mm}$ L48 with 44 rounds.

HEAT Vo $-1100 \mathrm{~m} / \mathrm{s}$. Effective range $-1650 \mathrm{~m} 1 \times 7,62 \mathrm{~mm}$ co-axial M.G.

Laser range finder, COTAC automatic fire control system. AVA.M.G. and smoke bomb launchers can be fitted.
Mobility:

Hispano-Suiza 276 b.h.p. water-cooled diesel. $4 \mathrm{~F}$ । $\mathrm{R}$ gearbox, hydraulic torque convertor. Hydraulic suspension with variable ground clearance. Skid steering. $85 \mathrm{~km} / \mathrm{h}$ road speed, $800 \mathrm{~km}$ range. $60^{\circ}$ slope, $1,6 \mathrm{~m}$ trench, $70 \mathrm{~cm}$ step.

Amphibious without prepara-

tion, $7 \mathrm{~km} / \mathrm{h}$ (hydrojets).

\section{Dimensions:}

$6,2 \mathrm{~m} \times 2,87 \mathrm{~m} \times 2,2 / 2,56 \mathrm{~m}$ 15 tonnes combat laden.

Only the skid steering might provide problems, but these have probably been ironed out. Available related vehicles include an armoured personnel carrier (AMX-10RP) and a Hot armed anti-tank vehicle (AMX-10RM). No great difficulty should be encountered in developing the other required variants: most of them already exist in the tracked versions. Thus it would be possible to use only one basic chassis for all the major combat vehicles of the brigade, with all the cost and maintenance related advantages inherent to this approach. The envisaged brigade could, in fact, comprise only six basic vehicle types: $4 \times 4$ and $6 \times 6$ combat, 1-, 2-, 5- and 10-ton trucks. The $4 \times 4$ chassis could be that of the Eland, an adaptation of which could well fill the Ferret/Vixen slot. Other possibilities in this regard would be the Israeli RBY Mk1 and the United States, $\mathrm{XR} 311$ scout vehicles. The $6 \times 6$ chassis refer to the Amx-10R series. However, as the Ratel is already in production, it might be desirable to utilise it for as many variants as possible, accepting the penalties of an extra type. The AMX-10RC and RM, however, will probably have to be procured as systems if too great a time-lag and development costs are to be avoided. Other more or less suitable vehicles are, of course, also available, notably the Brazilian EE-9 Cascaval although this does suffer from the inadequacies of having a two man turret. The AMX-10RC is, however, the ideal vehicle and is virtually the backbone of the entire suggested system.

First consideration of the above may well induce a virtual state of shock, both at the complexities and costs of a possible adoption of the system and the apparent rigidity thereof. Its adoption would, indeed, require much effort 
and expense but further consideration will, it is hoped, reveal its inherent flxibility. This paper has not attempted to cover even all the major possibilities. It has merely sought to provide a basis for flexible minds to work on and with. We have a long tradition of flexible and imaginative military thinking, let us return to it!

The mechanised brigades could become the spiritual descendants of the old Boer Commandos. Handled accordingly they should prove even more successful. 10

10. Unlike their forebears, they would have behind them a strong industrial base and a powerful strategic reserve to exploit their success. 